\title{
Maternal Mortality Risk Factors in Regional Hospital of Burkina Faso
}

\author{
Léon G. Blaise Savadogo ${ }^{1,2,}$, , Aminata Zombra ${ }^{3}$, Cécile Tamini ${ }^{4}$, Maurice Kinda ${ }^{1}$, \\ Philipe Donnen 5 \\ ${ }^{1}$ Department of Epidemiology and Public Health-Child and Mother Health, Nutrition and Survival \\ Unit-Institut Supérieur des Sciences de la Santé, Université Polytechnique, Bobo Dioulasso, Burkina Faso \\ ${ }^{2}$ CR2, Epidemiology-Biostatistics-Clinical Research, School of Public Health, Université Libre de Bruxelles, \\ Bruxelles, Belgique \\ ${ }^{3}$ Centre Hospitalier Régional, Banfora, Burkina Faso \\ ${ }^{4}$ Ecole National de Santé Publique, Bobo Dioulasso, Burkina Faso \\ ${ }^{5}$ CR3 - Politiques et Systèmes de Santé-Santé Internationale, School of Public Health, Université Libre de \\ Bruxelles, Bruxelles, Belgique \\ Email: "gueswende@hotmail.com
}

Received 17 February 2014; revised 17 March 2014; accepted 25 March 2014

Copyright (C) 2014 by authors and Scientific Research Publishing Inc.

This work is licensed under the Creative Commons Attribution International License (CC BY). http://creativecommons.org/licenses/by/4.0/

(c) (i) Open Access

\section{Abstract}

Individual causes and community determinants are synergic in maternal death occurrence. This study aimed to identify maternal mortality risk factors in a regional hospital. Material and Methods: This was a retrospective cohort study from data of 1807 hospitalized women. To identify maternal mortality risks factors, mortality hazard ratio (HR CI95\%) has been calculated in univariate analysis and Cox proportional hazard model. Results: During hospitalization, 30 maternal deaths occurred. From Cox regression, adjusted mortality HR confirmed that women age older than 35 (HR = 2.5, CI95\%: [1.2 - 5.7] and younger than 19 (HR = 3.02, CI95\%: [1.5 - 6.7]); distance to hospital $\geq 10 \mathrm{Km}$ (HR = 4.1, CI95\%: [1.8 - 9.4]; multiple deliveries (HR = 2.4, CI95\%: [1.1 - 7.3]), less ante natal care ( $<3$ visits) $(\mathrm{HR}=3.03, \mathrm{CI} 95 \%$ : $[0.97-9.48])$; obstetrical maternal mortality directs causes $(\mathrm{HR}=2.31, \mathrm{CI95 \%}$ : $[1.7-6.21])$ and emergently reference $(\mathrm{HR}=3.5, \mathrm{CI95 \%}$ : $[1.8$ 8.32]) were maternal mortality risk factors. Conclusion: In this regional hospital of low income country, identified maternal mortality factors are related to women socio-economic determinants and quality prenatal or obstetric care access. Interventions to reduce maternal mortality rate should be conducted within both household and women socio-economic status development and in maternal health and obstetric care strengthening.

\footnotetext{
${ }^{*}$ Corresponding author.
}

How to cite this paper: Savadogo, L.G.B., Zombra, A., Tamini, C., Kinda, M. and Donnen, P. (2014) Maternal Mortality Risk Factors in Regional Hospital of Burkina Faso. Open Journal of Epidemiology, 4, 57-62. 


\section{Keywords}

\section{Maternal Mortality, Risk Factors, Regional Hospital, Burkina Faso}

\section{Introduction}

Goal five of the Millennium Development Goals (MDGs) aims to achieve three-quarter reduction of maternal mortality by 2015 from 1990 level. But despite efforts and global trends on maternal death, international health issue about maternal health in low-income countries continues to be focused on maternal deaths. Trends in maternal mortality rate showed a decline of $47 \%$ in 2010 from levels in 1990. Sub-Saharan Africa accounted for $56 \%$ of the total rate in 2010. Lack of skilled routine and emergency care is the underline linked cause of most of the maternal death [1]. Poor availability and quality of maternity services are determinant on maternal death occurrence [2].

Individual causes and community determinants are synergic in maternal death occurrence. Most of the time maternal death is associated with both poor socioeconomic situation (global poverty, women's economic situation, number of pregnancy, number of deliveries, women education) and serious lack of health resources (health care facilities, maternities, medicines, skilled health providers, prenatal preventive care). Large burden of pregnancy-related complications and associated disabilities and high maternal mortality rate are linked. For maternal death reduction, many key areas have to be combined: investment in maternal health promotion and primary care, in women education and global socioeconomic development (transport, nutrition and food security, women employment and social status etc...). When maternal death occurs in hospital, it can indicate a lack of timely improved health care. It is urgent to ensure that quality of care provided in hospital is optimal. The objective of this study was to identify maternal mortality risk factors in regional hospital of Burkina Faso few years from 2015 to purpose efficient actions.

\section{Material and Methods}

\subsection{Study Design and Site}

This was a retrospective cohort study. The study covered the period of one year, from January 1 to December 31, 2009. The study site was the maternity of Banfora regional hospital in Burkina Faso Cascades region area. At this maternity, skilled midwifes staff, leaded by a gynecologist and obstetrician medical doctor, was in charge of care providing.

\subsection{Study Population}

The study has been conducted from data of hospitalized women during pregnancy, delivery, or postpartum period. During the considered period, all hospitalized cases were considered.

\subsection{Study Samples Size}

Data of 1807 women have been considered for analysis.

\subsection{Data Collection}

Trained research midwife, not included in the maternity staff, collected data on women socio-demographic (age, education, marital status, occupation, distance to hospital, number of pregnancy, parity), antenatal visit, delivery mode, cause of death. Data have been recorded from patient's clinical document. The instrument for individual patient data collection was a pre-tested data case form.

\subsection{Statistical Analyses}

Usual statistics methods were applied. We used Pearson's Chi square test or Fisher's exact test to compare proportions. Mortality hazard ratio (HR) with confidence interval (CI95\%) have been calculated in univariate analysis and Cox proportional hazard models has been used in multivariate analysis to identify maternal mortality 
risks factors. Statistical significance level was 0.05. The data were analyzed using SPSS software version 20.

\section{Results}

The women Socio-demographics characteristics at admission to the maternity are given in Table 1 .

From the 1807 women, 30 maternal deaths occurred during hospitalization, in-hospital maternal mortality rate was $1.66 \%$. From the 30 maternal deaths, 11 occurred at ante partum (pregnancy) period (37\%), 4 deaths at per partum (13\%), 11 deaths at post partum (37\%) and 4 deaths at post-abortum period (13\%). We observed that $90 \%$ of the 30 maternal deaths occurred within the first 24 hours of the hospitalization.

On the 30 maternal deaths, 16 deaths (53.33\%) occurred due to obstetric directs causes: hemorrhage (3.33\%), infection (13.33\%), distocia (6.65\%), eclampsia (16.67\%), abortion (13.32\%) and uterine rupture (1.04\%); 14 maternal deaths (46.67\%) occurred due to indirect causes: anemia (30\%), HIV (3.33), malaria (3.33\%), peritoneal sepsis (3.33), renal insufficiency (3.33\%), post partum tetanus (3.33\%).

Table 1. Women Socio-demographics characteristics at admission to the maternity.

\begin{tabular}{|c|c|c|}
\hline & $\mathrm{n}$ & Percentage \\
\hline \multicolumn{3}{|l|}{ Women age group (years) } \\
\hline $11-14$ & 2 & 0.11 \\
\hline $15-19$ & 354 & 19.59 \\
\hline $20-24$ & 491 & 27.17 \\
\hline $25-29$ & 403 & 22.3 \\
\hline $30-34$ & 322 & 17.81 \\
\hline $35-39$ & 184 & 10.18 \\
\hline $40-44$ & 42 & 2.32 \\
\hline $45-49$ & 9 & 0.49 \\
\hline \multicolumn{3}{|l|}{ Marital status } \\
\hline Married or in a relationship & 1677 & 92.80 \\
\hline Single & 130 & 7.20 \\
\hline \multicolumn{3}{|l|}{ Distance to hospital } \\
\hline$<10 \mathrm{~km}$ & 1197 & 66.24 \\
\hline$>10 \mathrm{~km}$ & 610 & 33.76 \\
\hline \multicolumn{3}{|l|}{ Women main Occupation } \\
\hline House mother & 1607 & 88.93 \\
\hline Working with salary & 66 & 3.65 \\
\hline Students & 79 & 4.37 \\
\hline Informal sector & 55 & 3.04 \\
\hline \multicolumn{3}{|l|}{ Gestity } \\
\hline First & 485 & 26.84 \\
\hline Multiple & 1322 & 73.16 \\
\hline \multicolumn{3}{|l|}{ Parity } \\
\hline None & 535 & 29.61 \\
\hline One & 387 & 21.42 \\
\hline $2-3$ & 552 & 30.55 \\
\hline$>3$ & 333 & 18.43 \\
\hline
\end{tabular}


In univariate analysis, an increased maternal mortality risk have been founded for women: being older than 35 years $(\mathrm{HR}=2.98,95 \% \mathrm{CI}: 1.06$ - 6.34); being younger than 19 years $(\mathrm{HR}=2.53$, 95\%CI: 1.01 - 5.03); distance to hospital $\geq 10 \mathrm{~km}(\mathrm{HR}=6.45,95 \% \mathrm{CI}$ : $(2.78$ - 14.94); multiple deliveries (HR = 3.59, 95\%CI: 1.38 - 9.36); less antenatal care $(<3$ visits) (HR $=3.03,95 \% \mathrm{CI}$ : $1.02-9.48)$; obstetrical mortality directs causes (HR $=4.51$, 95\%CI: 2.08 - 9.79); emergently referred patients (HR = 5.83, 95\%CI: 2.52 - 13.52).

From Cox regression, adjusted mortality HR confirmed that, women age older than 35y (HR $=2.5$, CI95\%: (1.2 - 5.7)) and younger than 19y (HR = 3.02, CI95\%: c1.5 - 6.7)); distance to hospital $\geq 10 \mathrm{Km}$.

$(\mathrm{HR}=4.1$, CI95\%: $(1.8$ - 9.4)); multiple deliveries $(\mathrm{HR}=2.4$, CI95\%: $(1.1-7.3]))$, less ante natal care $(<3$ visits) (HR = 3.03, CI95\%: (0.97 - 9.48)); obstetrical maternal mortality directs causes (HR = 2.31, CI95\%: (1.7 - 6.21)) and emergently reference (HR = 3.5, CI95\%: $(1.8$ - 8.32)), were maternal mortality risk factors (Table 2).

Table 2. Univariate maternal mortality analysis and Cox proportional hazard ratio model for maternal mortality.

\begin{tabular}{|c|c|c|c|c|c|c|}
\hline & \multicolumn{4}{|c|}{ Univariate analysis } & \multicolumn{2}{|c|}{ Cox regression } \\
\hline & $\mathbf{n}$ & Maternal Mortality rate & HR (95\%CI) & $\mathbf{p}$ & HR (95\%CI) & $\mathbf{p}$ \\
\hline \multicolumn{7}{|l|}{ Women age group (y) } \\
\hline $11-19$ & 356 & 2.53 & $2.2[1.06-5.03]$ & & $2.5[1.2-5.7]$ & \\
\hline $20-34$ & 1216 & 1.15 & 1.00 & 0.04 & 1.00 & 0.02 \\
\hline$>=35$ & 235 & 2.98 & $2.64[1.06-6.34]$ & & $3.02[1.5-6.7]$ & \\
\hline \multicolumn{7}{|l|}{ Delivery Mode } \\
\hline Caesarean & 173 & 1.16 & $1.23[0.27-5.49]$ & 0.88 & & \\
\hline Vaginal & 1167 & 0.94 & 1.00 & & & \\
\hline \multicolumn{7}{|l|}{ Distance to hospital } \\
\hline$\geq 10 \mathrm{Km}$ & 610 & 3.77 & $6.45[2.78-14.94]$ & $<0.001$ & $4.1[1.8-9.4]$ & $<0.001$ \\
\hline$<10 \mathrm{Km}$ & 1197 & 0.58 & 1.00 & & 1.00 & \\
\hline \multicolumn{7}{|l|}{ Women occupation } \\
\hline House mother & 1575 & 1.84 & $4.27[0.58-31.21]$ & 0.08 & & \\
\hline Others* & 232 & 0.43 & 1.00 & & & \\
\hline \multicolumn{7}{|l|}{ Gestity } \\
\hline First & 485 & 1.24 & 1.00 & 0.39 & & \\
\hline Multiple & 1322 & 1.82 & $1.47[0.60-3.57]$ & & & \\
\hline \multicolumn{7}{|l|}{ Parity } \\
\hline No parity & 535 & 1.31 & $1.20[0.41-3.56]$ & & $1.1[0.2-3.7]$ & \\
\hline Primiparity & 387 & 1.03 & $0.95[0.27-3.35]$ & & $0.9[0.24-3.2]$ & 0.001 \\
\hline Low parity & 552 & 1.09 & 1.00 & 0.005 & 1.00 & \\
\hline Multiparity & 333 & 3.90 & $3.59[1.38$ - 9.36] & & $2.4[1.1-7.3]$ & \\
\hline \multicolumn{7}{|l|}{ Antenatal consultation } \\
\hline$<3$ & 697 & 1.58 & $3.03[0.97-9.48]$ & 0.04 & $3.03[0.97-9.48]$ & 0.02 \\
\hline$\geq 3$ & 769 & 0.52 & 1.00 & & 1.00 & \\
\hline \multicolumn{7}{|l|}{ Diagnostic } \\
\hline Obstetrical direct causes & 616 & 3.41 & $4.51[2.08-9.79]$ & $<0.001$ & $2.31[1.7-6.21]$ & $<0.001$ \\
\hline Indirect causes & 1191 & 0.76 & 1.00 & & 1.00 & \\
\hline \multicolumn{7}{|l|}{ Women admission mode } \\
\hline Referred (evacuated) & 642 & 3.58 & $5.83[2.52-13.52]$ & $<0.001$ & $3.5[1.8-8.32]$ & $<0.001$ \\
\hline Not referred & 1140 & 0.61 & 1.00 & & 1.00 & \\
\hline
\end{tabular}

*Others: women working with salary, women working in informal sector. 


\section{Discussion}

This was a retrospective cohort study with related limitations. Data have been collected over one year and limited to in-hospital patients. In rural regions, all women during pregnancy, delivery or postpartum period who need to be hospitalized don’t attend hospital for treatment.

Maternal mortality occurred between hospital attended patients is not acceptable. In this regional hospital of low income country, maternal mortality remains high (30 maternal deaths a year). It is important to provide quality care to women attending to that hospital. The analysis of the maternal mortality risk factors of hospitalized women showed that maternal mortality is directly related to poverty.

Number of authors, in low incomes countries, reported maternal individual factors (socioeconomic status, demographic, obstetric complications, infectious diseases prevalence) and village or community level factors (access to prenatal or obstetric cares, distance) as maternal mortality risk factors [3]-[8].

In our study, the identified risk factors were women's socioeconomics related factors: women age older than 35 and younger than 19, distance to hospital, multiple deliveries, less ante natal care.

Multiple deliveries affect maternal heath [9]-[12]. Women age (older than 35y or younger than 19y) added to women strong physical effort (overburden house work or labor), common in low income countries rural setting, can be synergetic in increasing maternal health risk [13] [14].

Lack of prenatal health care (prenatal visit) is a factor emphasizing maternal risk. Amy poverty related factors underling this lack of prenatal visit (low demand because of low education, women low power at home end in the community for decision, women lower economic status) [12] [15] [16]. Obstetrical maternal mortality directs causes (hemorrhage, infection, distocia, eclampsia, abortion and uterine rupture) and emergently references were maternal death risk factors. These maternal mortality causes can be prevented with quality maternal care adequate obstetrical care. But distance to hospital or to a skilled obstetric care provider can be a maternal mortality risk factor [17]. Low viability of transport is synergetic to distance to increase maternal mortality risk.

Observed indirect causes of maternal death in our study (anemia, HIV, malaria) are diseases closely associated with poverty [18]-[20].

\section{Conclusion}

In this regional hospital of low income country, identified maternal mortality factors are related to women socioeconomic determinants and quality prenatal or obstetric care access. These findings remind governments and international development agencies, that, if worldwide maternal mortality declines, its remains a big challenge in African low income countries. In these countries, interventions to reduce maternal mortality rate should be conducted within both household and women socio-economic status development and in maternal health and obstetric care strengthening in term of access and quality. In low income countries, building effective partnership between maternal health promoting programs and socioeconomic development programs for reducing maternal mortality can be an effective working area.

\section{Acknowledgements}

Commission universitaire pour le développement (CUD), Belgique.

\section{References}

[1] WHO (2012) Trends in Maternal Mortality: 1990 to 2010. WHO, UNICEF, UNFPA and The World Bank estimates. WHO.

[2] Paxton, A. and Wardlaw, T. (2011) Are We Making Progress in Maternal Mortality? The New England Journal of Medicine, 364, 1990-1993. http://dx.doi.org/10.1056/NEJMp1012860

[3] Fawole, A.O., Shah, A., Fabanwo, A.O., Adegbola, O., Adewunmi, A.A., Eniayewun, A.B., Dara, K., El-Ladan, A.M., Umezulike, A.C., Alu, F.E., Adebayo, A.A., Obaitan, F.O., Onala, O.E., Usman, Y., Sullayman, A.O., Kailani, S. and Sa'id, M. (2012) Predictors of Maternal Mortality in Institutional Deliveries in Nigeria. African Health Sciences, 12, 32-40.

[4] Nabukalu, D., Klipstein-Grobusch, K., Herbst, K. and Newell, M-L. (2013) Mortality in Women of Reproductive age in Rural South Africa. Glob Health Action, 6, Article ID: 22834. http://dx.doi.org/10.3402/gha.v6i0.22834

[5] De Moraes, A.P.P., Barreto, S.M., Passos, V.M.A., Golino, P.S., Costa, J.E. and Vasconcelos, M.X. (2013) Severe 
Maternal Morbidity: A Casecontrol Study in Maranhao, Brazil. Reproductive Health, 10, 11. http://dx.doi.org/10.1186/1742-4755-10-11

[6] Illah, E., Mbaruku, G., Masanja, H. and Kahn, K. (2013) Causes and Risk Factors for Maternal Mortality in Rural Tanzania—Case of Rufiji Health and Demographic Surveillance Site (HDSS). African Journal of Reproductive Health, 17, 119-130.

[7] Saleh, W.F., Ragab, W.S. and Aboulgheit, S.S. (2013) Audit of Maternal Mortality Ratio and Causes of Maternal Deaths in the Largest Maternity Hospital in Cairo, Egypt (Kasr Al Aini) in 2008 and 2009: Lessons Learned. African Journal of Reproductive Health, 17, 105-109.

[8] Garba, M., Nayama, M., Alio, A.P., Holloway, M.L., Hamisu, B.S. and Salihu, H.M. (2011) Maternal Mortality in Niger: A Retrospective Study in a High Risk Maternity. African Journal of Medicine \& Medical Sciences, 40, 393-397.

[9] Kane, T.T., El-Kady, A.A., Saleh, S., Hage, M., Stanback, J. and Potter, L. (1992) Maternal Mortality in Giza, Egypt: Magnitude, Causes, and Prevention. Studies in Family Planning, 23, 45-57. http://dx.doi.org/10.2307/1966827

[10] Alauddin, M. (1986) Maternal Mortality in Rural Bangladesh: The Tangail District. Studies in Family Planning, 17, 13-21. http://dx.doi.org/10.2307/1966951

[11] Walker, G., Affette, J.A., Mccaw, M., Ashley, D.E.C. and Bernard, G.W. (1986) Maternal Mortality in Jamaica. The Lancet, 327, 486-488. http://dx.doi.org/10.1016/S0140-6736(86)92939-9

[12] Chowdhury, M., Botlero, E.R., Koblinsky, M., Saha, S.K., Dieltiens, G. and Ronsmans, C. (2007) Determinants of Reduction in Maternal Mortality in Matlab, Bangladesh: A 30 Year Cohort Study. The Lancet, 370, 1320-1328. http://dx.doi.org/10.1016/S0140-6736(07)61573-6

[13] Bonzini, M., Coggon, D. and Palmer, K. (2007) Risk of Prematurity, Low Birth Weight and Preeclamsia in Relation to Working Hours and Physical Activities: A Systematic Review. Journal of Occupational and Environmental Medicine, 64, 228-243. http://dx.doi.org/10.1136/oem.2006.026872

[14] Mozurkewich, E.L., Luke, B. and Avni, M. (2000) Working Conditions and Adverse Pregnancy Outcome: A Meta-Analysis. Obstetrics and Gynecology, 95, 623-635. http://dx.doi.org/10.1016/S0029-7844(99)00598-0

[15] Jayachandran, S. and Lleras-Muney, A. (2009) Life Expectancy and Human Capital Investments: Evidence from Maternal Mortality Declines. Quarterly Journal of Economics, 124, 349-397. http://dx.doi.org/10.1162/qjec.2009.124.1.349

[16] Okonofua, F.E., Abejide, A. and Makanjuola, R.A. (1992) Maternal Mortality in Ile-Ife, Nigeria: A Study of Risk factors. Studies in Family Planning, 23, 319-324. http://dx.doi.org/10.2307/1966529

[17] Maine, D., Akalin, M.Z., Chakraborty, J., Francisco, A. and Strong, M. (1996) Why Did Maternal Mortality Decline in Matlab? Studies in Family Planning, 27, 179-187. http://dx.doi.org/10.2307/2137952

[18] Granja, A.C., Machungo, F., Gomes, A., Bergström, S. and Brabin, B. (1998) Malaria Related Maternal Mortality in Urban Mozambique. Annals of Tropical Medicine and Parasitology, 92, 257-263. http://dx.doi.org/10.1080/00034989859816

[19] Ahmed, Y.P., Mwaba, C., Chintu, J.M., Grange, A., Ustianowski, A. and Zumla, N. (1999) A Study of Maternal Mortality at the University Teaching Hospital, Lusaka, Zambia: The Emergence of Tuberculosis as a Major Non-Obstetric Cause of Maternal Death. International Journal of Tuberculosis and Lung Disease, 3, 675-680.

[20] Khan, M., Pillay, T., Moodley, J.M. and Connolly, C.A. (2001) Maternal Mortality Associated with Tuberculosis-HIV-1 Co-Infection in Durban, South Africa. Aids, 15, 1857-1863. http://dx.doi.org/10.1097/00002030-200109280-00016 